Revista Aspas

ppgac - USP

Especial

\title{
QUESTÕES DE GÊNERO: DESVELANDO A DESIGUALDADE NO MERCADO DE TRABALHO DA ILUMINAÇÃO CÊNICA NO BRASIL
}

\section{GENDER ISSUES: UNVEILING INEQUALITY IN THE LABOR MARKET OF LIGHTING DESIGN IN BRAZIL}

\section{CUESTIONES DE GÉNERO: REVELANDO LA DESIGUALDAD EN EL MERCADO LABORAL DE LA ILUMINACIÓN ESCÉNICA EN BRASIL}

\author{
Nadia Moroz Luciani, Gabriela Valcanaia \\ e Milena Sugiyama
}

Nadia Moroz Luciani

Docente e Pesquisadora do curso de Bacharelado em Artes

Cênicas da FAP - Campus de Curitiba II da Universidade Estadual do Paraná - UNESPAR. Graduada em Design pela Universidade Federal do Paraná - UFPR, Mestre em Teatro pelo PPGT-CEAC-UDESC e Doutora em Artes Cênicas pelo PPGAC-

ECA-USP. Designer e iluminadora cênica.

Gabriela Valcanaia

Estudante do Curso de Licenciatura em Teatro na FAP - Campus de Curitiba II da UNESPAR. Graduada em Artes Cênicas pela

Universidade Estadual do Paraná - UNESPAR, bolsista de Iniciação Científica da UNESPAR com recursos da Fundação Araucária. Atriz, produtora e iluminadora cênica.

Milena Sugiyama Graduada em Artes Cênicas pela Universidade Estadual do Paraná - UNESPAR. Atriz, produtora e iluminadora cênica. 


\begin{abstract}
Resumo
Este artigo pretende, por meio de argumentos, depoimentos e percepções, revelar - para depois poder remover - o véu de igualdade que encobre a realidade do mercado de trabalho da iluminação cênica brasileiro, considerando as relações e as condições de trabalho das mulheres dedicadas ao ramo. Para tanto, lança um olhar atento às vozes e experiências de diferentes gerações de mulheres, com enfoque na emergência de movimentos digitais de iluminadoras e técnicas de luz durante a pandemia da COVID-19 no Brasil. Demonstra, complementado por uma bibliografia e referenciais específicos dedicados a questões de gênero e de desigualdades no mercado de trabalho, a realidade do cotidiano e os desafios enfrentados por essas mulheres no decorrer de suas atuações e carreiras profissionais.
\end{abstract}

Palavras-chave: iluminação cênica, gênero, mulheres artistas, visibilidade, força de trabalho, desigualdade.

\section{Abstract}

This article intends, through arguments, testimonies and perceptions, reveal - in order to remove - the veil of equality that covers the reality of the Brazilian professional labor market of lighting design, considering the relationships and the working conditions of women dedicated to the field. To this end, it takes a close look at the voices and experiences of different generations of women, focusing on the emergence of digital movements of women lighting designers and techniques during the COVID-19 pandemic in Brazil. It demonstrates, complemented by a bibliography and specific references dedicated to issues of gender and inequalities in the labor market, the reality of daily life and the challenges faced by these women in the course of their work and professional careers.

Key-words: lighting design, gender, workforce, inequality

\section{Resumen}

Este artículo tiene como objetivo, a través de argumentos, testimonios y percepciones, revelar - para después quitar - el velo de igualdad que cubre la realidad del mercado laboral brasileño de la iluminación escénica, considerando las relaciones y las condiciones laborales de las mujeres dedicadas al campo. Para ello, analiza de cerca las voces y experiencias de diferentes generaciones de mujeres, centrándose en el surgimiento de movimientos digitales de iluminadoras y técnicas de iluminación durante 


\begin{abstract}
la pandemia de COVID-19 en Brasil. Demuestra, complementada con una bibliografía y referencias específicas dedicadas a temas de género y desigualdades en el mercado laboral, la realidad de la vida cotidiana y los desafíos que enfrentan estas mujeres en el transcurso de su trabajo y carrera profesional.
\end{abstract}

Palabras-clave: iluminación escénica, género, fuerza laboral, desigualdad.

Em 2020, durante o primeiro ano da pandemia da COVD-19, a emergência de movimentos e projetos de mulheres iluminadoras foi responsável por dar início a importantes debates sobre as questões de gênero no ramo da iluminação cênica no Brasil. Quando falamos, no título deste artigo, sobre as desigualdades no mercado de trabalho da iluminação, tendemos a pensá-las de maneira interseccional e considerar as diferentes realidades de iluminadoras, técnicas eletricistas, montadoras, assistentes e operadoras de luz. As relações profissionais estabelecidas entre homens e mulheres não podem ser simplificadas ou mesmo resolvidas na esfera individual, tendo em vista que gênero é uma ideologia fundante da sociedade ocidental e que as transformações necessárias para solucionar suas assimetrias são de ordem coletiva. Nesta abordagem, compreendemos gênero como uma construção histórica da modernidade, resultante da colonização e do capitalismo, que divide binariamente funções e atividades de corpos em relação à produção e à reprodução social a partir, principalmente, da construção e sustentação da ideia de dois sexos biológicos.

A partir de informações e depoimentos coletados por diferentes movimentos e projetos culturais, foi possível traçar um panorama das experiências e percepções sobre o mercado de trabalho da iluminação cênica do ponto de vista das mulheres. Sobre os dados coletados, as variantes mais significativas se apresentaram nas diferenças geracionais, de raça, classe, escolaridade e experiências de trabalho. Tais marcadores demonstram maneiras distintas pelas quais mulheres percebem e reivindicam oportunidades e condições de atuação neste mercado de trabalho específico. As entrevistas realizadas com as idealizadoras dos movimento e projetos iluMINA!, Mulheres na Luz, Mulheres na Técnica PA e Autobiografia de Todas 
Nós revelaram a forma como essas ações permitiram dar voz e revelar realidades e experiências dessas mulheres nos seus ambientes de trabalho.

Apesar da inegável presença das mulheres em todo tipo de atividade ligada à iluminação cênica, as relações de trabalho entre homens e mulheres seguem gerando situações nas quais mulheres são silenciadas, deslegitimadas, humilhadas, subestimadas e assediadas. Essas circunstâncias muitas vezes são envoltas em aparentes equidades e mascaradas sob a forma de galanteio, gentileza e cavalheirismo. Tais pretextos revelam os pressupostos ideológicos que constroem a visão dos homens sobre as mulheres em sociedade e, por consequência, alteram a maneira como veem e tratam suas colegas de trabalho. Somos diferentes, sim, mesmo entre mulheres, pelas subjetividades, competências, características identitárias e experiências de cada uma, mas enfatizamos como é importante desvelar essa ilusão de homogeneidade universal para que seja possível, então, pleitear respeito e dignidade no aprendizado e no exercício de nossa profissão.

\section{ARGUMENTO - ILUMINAÇÃO É TRABALHO DE HOMEM?}

A luz, como fenômeno físico, se faz presente desde as primeiras manifestações teatrais, bem como nas diversas práticas rituais que as antecederam, uma vez que a iluminação é, antes de tudo, uma questão de visibilidade, de tornar visível. A luz cênica, inicialmente realizada pelo aproveitamento da luz do sol, seguiu seu percurso com o uso de instrumentos para o manejo do fogo até sua substituição gradual pelas lâmpadas elétricas. Podemos afirmar que a iluminação de espetáculos é uma linguagem tecnológica e que o desenvolvimento de sua poética ocorreu simultaneamente ao aprimoramento de seus recursos e técnicas, sendo que, no Brasil,

[...] por um lado, a iluminação cênica começa a se tornar objeto de uma atenção e reflexão por parte da crítica especializada, constituindo-se como um dos elementos fundamentais da estética teatral moderna e, por outro, que esta atividade profissional começa a ser considerada em sua especificidade e autonomia, no decorrer das décadas de 1950 e 1960. (SOUZA, 2018, p. 24) 
O trato com a eletricidade exigiu que os edifícios teatrais agregassem a suas equipes eletricistas em espetáculo¹, responsáveis pela montagem, afinação e operação da luz cênica. Com o aumento da complexidade da cena teatral, as produções passaram a requerer mais efeitos e esses eletricistas começaram a realizar também concepções de luz. Com a virada do século XIX para o século $X X$, a iluminação passou de instrumento de visibilidade à scriptura do visível, conceito cunhado por Cibele Forjaz (2013), tornando-se uma linguagem específica, cujas funções simbólicas foram se expandindo até alcançar a expressão e o status de manifestação artística do espetáculo, que pretende, pela performatividade da luz, acessar a percepção do espectador (LUCIANI, 2020).

A ampliação de recursos, bem como da variedade e quantidade de equipamento utilizado, transformou significativamente a linguagem da luz até o que vemos hoje nos palcos e nas telas. Ainda no início do século $X X, a$ atividade da iluminação cênica foi dividida em duas áreas: a criação e a montagem. Com a chegada das tecnologias digitais, ela alcançou tamanho grau de especificidade que surgiram, além dessas, diversas outras profissões: assistência de luz, operação de luz, operação de canhão, montagem de solo, montagem aérea em grandes alturas (rigging), afinação, programação de mesa, programação de moving, técnica em eletricidade, técnica em eletrônica, entre tantas outras surgidas de acordo com os avanços tecnológicos e a crescente demanda de novos efeitos por parte das produções de espetáculos, shows e eventos. Mesmo que exercidas majoritariamente por homens, é importante ressaltar que nenhuma dessas atividades apresenta, para sua realização, qualquer demanda específica que justifique a hegemonia pelo gênero masculino.

O patriarcado, uma ideologia que se baseia na dominação dos homens e na subordinação das mulheres, está presente na esfera familiar, no âmbito trabalhista, na mídia mercadológica e na política. Sendo um sistema ideológico, ele atua na dinâmica social como um todo: individualmente no inconsciente de homens e mulheres e coletivamente através das categorias

\footnotetext{
${ }^{1}$ Como designado no Brasil pela Lei 6.533 e pelo Decreto 82.385 de 1978.
} 
sociais de gênero. À luz do trabalho de Naomi Wolf (1992) e Gaya Spivak (2010), pudemos analisar discursos inconscientes e aparentemente inofensivos de iluminadores e pesquisadores da iluminação que ignoram ou subestimam, em seus trabalhos e estudos, a presença e a atuação das mulheres. Segundo Spivak, é preciso atentar para os elementos do discurso que não são reconhecidos durante a articulação, visto que é possível, através deles, identificar a ideologia que os constrói. A recorrência do estereótipo imagético da iluminação cênica como um trabalho de homem, mesmo com a indiscutível participação das mulheres, é um indicativo de que a relação de gênero neste mercado de trabalho no Brasil não é igualitária, mesmo que o discurso esteja, muitas vezes, envolto em um véu de igualdade.

Há uma insistência, no meio da iluminação, em argumentar que a abordagem do tema deva tratar apenas da luz, privilegiando questões técnicas e poéticas da matéria, excluindo assuntos políticos e identitários relativos à profissão. Essa premissa ignora, entre outras, que os processos criativos envolvem questões subjetivas, e que, portanto, o gênero, a classe e a raça dos e das profissionais alteram o resultado final produzido por eles ou por elas. Além disso, ignora, sobretudo, que o mercado de trabalho da iluminação é, também, produto da nossa sociedade e que, portanto, funciona a partir de ideais racistas, misóginos e capacitistas. Nesse discurso negacionista, é possível identificar que os homens não se compreendem como produtos da ideologia de gênero, mas constroem sua noção sobre si como o "um" e sobre as mulheres como o "outro", determinando-as como "o diferente" a partir de si mesmos e de suas vivências dentro da masculinidade (BEAUVOIR, 2016, p. 14). Logo, conclui-se que os estudos e as teorias a respeito da luz produzidas até então, não se desobrigam da discussão de gênero, mas posicionam-se a partir das condições de privilégio dos homens. Por essa cegueira ignorante, não percebem que as questões do trabalho com luz investigadas e debatidas são, na verdade, questões postas sobre o mercado de trabalho da luz dos homens. Sem essa compreensão da posição assumida pelo orador, seja ele um professor ou um mestre/educador em iluminação, ele estará reproduzindo uma narrativa alinhada ao patriarcado enquanto episteme, que tem como função política a programação sobre as 
gerações mais novas e a população em geral. Pode-se concluir, então, que o entendimento da iluminação cênica como trabalho de homem não se deve a uma suposta incompetência, incapacidade ou desinteresse das mulheres sobre a luz, mas a uma construção ideológica de gênero presente nos discursos de maneira velada. Portanto, para retirarmos o véu que encobre a desigualdade nesse mercado, é necessário compreender as crenças e os valores sociais que a sustentam, identificando suas origens para, finalmente, poder desconstrui-los.

\section{ARGUMENTO - QUESTÕES DE GÊNERO NA ILUMINAÇÃO CÊNICA}

Considerando o desenvolvimento da iluminação cênica como mercado profissional, não podemos deixar de refletir sobre o modo como o viés de gênero se faz presente na distribuição das funções e na maneira como isso reflete na remuneração e nas relações entre profissionais da luz nos seus ambientes de trabalho. Os movimentos feministas e a crescente atuação de mulheres em espaços públicos resultaram em importantes transformações, com ênfase para as mudanças no papel social da mulher. Na década de 1970, uma considerável queda na taxa de fecundidade ${ }^{2}$ ocorreu paralelamente à expansão da escolaridade, ao acesso das mulheres às universidades e à sua inserção no mercado de trabalho. Não obstante, os cuidados da casa e da família seguiram sob sua responsabilidade, ampliando seu tempo de dedicação ao trabalho, tanto dentro, sem remuneração, quanto fora de casa. Com políticas sociais ${ }^{3}$ insuficientes no que diz respeito ao arrefecimento das tensões na articulação entre família (atividades reprodutivas) e profissão (atividades produtivas), a divisão do trabalho por gênero no Brasil afetou

\footnotetext{
${ }^{2}$ Segundo Montali (2017) a taxa de fecundidade cai acentuadamente a partir de 1970 até a atualidade no Brasil, de um patamar de 6,3 filhos por mulher entre 1940 e 1960, passa para 5,5 em 1970, para 4,4 em 1980, 2,9 em 1991, 2,4 em 2000 e 1,9 filhos em 2010.

${ }^{3}$ Algumas garantias legais que estão sendo pautadas no Brasil por organizações de mães pautam que o auxílio à maternidade que se estendam além dos 4 meses iniciais, como a garantia de complementação de renda para as mães durante os dois primeiros anos de vida da criança, para que elas possam trabalhar fora com uma carga de trabalho menor e não comprometer a formação de sua filha e nem sua autonomia financeira; ampliação do tempo de licença paternidade; criação de mais creches públicas e a sua ampliação para o tempo integral.
} 
diretamente mulheres que, não raro, se viram forçadas a abdicar de um aspecto em detrimento do outro.

Apesar disso, a participação das mulheres no mercado de trabalho brasileiro segue crescendo. No setor das ciências e das artes, por exemplo, foram criados, somente em $2018,134.409$ novos empregos, dos quais $91,1 \%$ foram ocupados por mulheres ${ }^{4}$. Mesmo que esse dado pareça promissor, 0 crescimento se deu em funções já ocupadas por uma maioria feminina e o salário das mulheres permaneceu sendo, em média, 85,7\% dos salários concedidos aos homens. A presença de mulheres no mercado é marcada, portanto, pela segregação ocupacional e pela desigualdade salarial. A distribuição de funções produtivas a um ou ao outro gênero é regida tanto pelo poder social ${ }^{5}$ e o impacto econômico dessas funções quanto pelas atribuições demandadas para a execução do trabalho. A iluminação cênica, por exemplo, por envolver especificidades técnicas como a eletricidade, a tecnologia e o manuseio de equipamentos de grande porte, é vista socialmente como uma área de atuação masculina. No entanto, a participação de mulheres no campo da iluminação e das artes em geral é facilmente comprovada em céleres buscas investigativas, sobretudo quando consideramos também a docência e a pesquisa acadêmica.

De acordo com Beauvoir (2016, p. 84), na Idade da Pedra, homens e mulheres constituíam duas classes distintas, mas havia igualdade entre elas. Enquanto o homem era responsável por caçar e pescar, a mulher realizava outras tarefas como a cerâmica, a tecelagem e a jardinagem, trabalhos igualmente produtivos. Porém, com a chegada da Idade dos Metais, a agricultura estendeu seus domínios, fazendo com que o homem recorresse ao serviço de outros homens, que ele reduziu à escravidão. Com isso surge a propriedade privada e a figura do homem como senhor da terra e dos escravos, tornando-o também proprietário da mulher. $\mathrm{O}$ discurso que compreende a mulher como objeto, parte de uma premissa biológica cujo

\footnotetext{
${ }^{4}$ Dados retirados da Relação Anual de Informações Sociais (RAIS), do Ministério da Economia, realizado entre os anos de 2014 e 2018, tendo como referência a situação em 31 de dezembro de cada ano.

${ }^{5} \mathrm{Em}$ atividades de governança pública e de liderança em organizações privadas a participação das mulheres segue sendo sub-representada.
} 
axioma é a binariedade, definindo-a como inferior e como sexo frágil. Em discursos que definem a iluminação como atividade essencialmente masculina, é comum ouvir justificativas que atestam a mulher como sendo mais fraca, sensível e emotiva do que o homem, além de, por ser mulher, não apresentar condições físicas para suportar e realizar as tarefas envolvidas. Esses argumentos, porém, perdem sentido se considerarmos que,

[...] desde que aceitamos uma perspectiva humana, definindo o corpo a partir da existência, a biologia torna-se uma ciência abstrata; no momento em que o dado fisiológico (inferioridade muscular) assume uma significação, esta surge desde logo como dependente de todo um contexto; a "fraqueza" só se revela como tal à luz dos fins que o homem se propõe, dos instrumentos de que dispõe, das leis que se impõe. (BEAUVOIR, 2016, p. 63)

A ideia de sexo frágil ignora, primariamente, as diferentes mulheridades 6 existentes, apagando vivências históricas de mulheres pobres e negras que, para sustentar suas famílias, assumiram jornadas duplas ou triplas de trabalho, cumprindo até, em muitas delas, funções de grande esforço físico. Sojourner Truth, depois de ouvir, em 1851 durante o Women's Rights Convention em Ohio nos Estados Unidos, pastores afirmarem que mulheres não deveriam ter os mesmos direitos que os homens porque seriam frágeis e intelectualmente débeis, levantou-se e disse:

\begin{abstract}
Aqueles homens ali dizem que as mulheres precisam de ajuda para subir em carruagens, e devem ser carregadas para atravessar valas, e que merecem o melhor lugar onde quer que estejam. Ninguém jamais me ajudou a subir em carruagens, ou a saltar sobre poças de lama, e nunca me ofereceram melhor lugar algum! E não sou uma mulher? Olhem para mim? Olhem para meus braços! Eu arei e plantei, e juntei a colheita nos celeiros, e homem algum poderia estar à minha frente. E não sou uma mulher? Eu poderia trabalhar tanto e comer tanto quanto qualquer homem - desde que eu tivesse oportunidade para isso - e suportar o açoite também! E não sou uma mulher? Eu pari treze filhos e vi a maioria deles ser vendida para a escravidão, e quando eu clamei com a minha dor de mãe, ninguém a não ser Jesus me ouviu! E não sou uma mulher? (TRUTH, 2014, n.p.)
\end{abstract}

\footnotetext{
${ }^{6} \mathrm{O}$ termo mulheridades é usado neste trabalho a fim de abarcar as diversidades do ser mulher, considerando as variações raciais, de gênero, sexualidade, idade/geração, classe social e corporalidades. A combinação desses fatores revela experiências coletivas e individuais que determinam os eixos de opressão vivenciados por cada grupo de mulheres.
} 
O conceito de sexo frágil não é um argumento fundamentado na biologia, mas em uma construção social que tem como finalidade beneficiar os homens na esfera pública e privada. Ademais, mesmo que assim fosse, o mercado de trabalho da iluminação não se restringe ao transporte, montagem e manipulação de equipamentos, como parece ser a premissa dos questionamentos sobre a capacidade física das mulheres para atuar nessa área. Para além dessas atividades, comprovadamente exercidas sem problemas também por mulheres, há a criação, programação e operação, funções que figuram igualmente no escopo da iluminação cênica e exigem conhecimentos de ordem técnica e de desenvolvimento criativo, o que desconstrói o argumento supracitado da necessidade exclusiva de habilidade ou força física para a execução do ofício. A iluminadora Nadia Luciani ouviu, no início de sua carreira, que "uma mulher iluminadora não deve ser tão mulher assim" (LUCIANI, 2015). Isso faz pensar que ao afirmar que uma mulher que exerce uma função socialmente atribuída a homens é menos mulher, o que está sendo alegado é que, ao exercer essa atividade, ela está negando sua essência feminina. Segundo Simone de Beauvoir,

[...] as mulheres nunca opuseram valores femininos aos valores masculinos; foram os homens, desejosos de manter as prerrogativas masculinas, que inventaram essa divisão: pretenderam criar um campo de domínio feminino - reinado da vida, da imanência - tão somente para nele encerrar a mulher. (BEAUVOIR, 2016, p. 100)

Quando uma mulher assume a responsabilidade pela coordenação e criação de projetos de iluminação, ela está, de alguma forma, subvertendo a ideia de feminilidade por ocupar um cargo de poder e força, tornando-se, numa ótica misógina, menos mulher. Esse tipo de argumento considera a mulher com base em sua feminilidade aparente e os homens em sua masculinidade viril. Segundo Naomi Wolf (1992), a feminilidade é um padrão de comportamento social com vista na submissão e no controle das mulheres. Ela se apresenta pela estética, mas age na construção da individualidade com efeitos de ordem política, uma vez que determina o papel social a ser desempenhado pelas mulheres. A reação contemporânea é violenta, porque 
a ideologia da beleza é a última das antigas ideologias femininas que ainda têm o poder de controlar aquelas mulheres que a segunda onda do feminismo teria tornado relativamente incontroláveis. Ela se fortaleceu para assumir a função de coerção social que os mitos da maternidade, domesticidade, castidade e passividade não conseguem mais realizar. Ela procura destruir, psicologicamente e às ocultas, tudo de positivo que o feminismo proporcionou às mulheres material e publicamente (WOLF, 1992, p. 13).

Os signos considerados femininos são relacionados à emoção e distanciados da razão, limitando as possibilidades de atuação das mulheres na sociedade. O ideal de mulher estabelecido exige que as meninas, desde o nascimento, cultivem em si a feminilidade, tenham seus corpos, mentes e saberes mutilados, dedicando seu tempo, energia e dinheiro na busca por padrões impostos, muitos deles inalcançáveis, tanto do ponto de vista estético, quanto de comportamento. Por outro lado, o padrão social da masculinidade é exercido pelos homens sem esforço, ao não se preocuparem com sua aparência estética, serem autocentrados, competitivos e agirem livremente com violência verbal e física - características importantes para a dominação. Feminilidade e masculinidade são conceitos que desprezam as subjetividades de mulheres e homens, mas sobretudo reforçam, desde a infância, que as relações entre ambos são baseadas na submissão e dedicação delas para atender aos desejos deles. Desse modo, impõem à mulher um papel objetificado, desacreditando e silenciando suas vontades e desejos.

No ramo de atividade da iluminação cênica, muito mais do que com iluminadoras criadoras, deparamo-nos com a figura de assistentes de luz. Muitas dessas mulheres são escolhidas para esta função por serem mais organizadas, sensíveis, atentas, disponíveis e cuidadosas, como admitem alguns iluminadores quando explicam sua preferência. Essa função e essas habilidades, tidas como ideais para o papel servil de assistente, acabam por se tornar essenciais na execução dos projetos de luz, uma vez que é ela quem se torna responsável por realizar muitas das tarefas envolvidas, ficando, porém, à sombra do iluminador. Ao contrário, quando uma mulher assume a posição de criadora, é comum ela precisar provar suas competências e 
capacidades para ser respeitada. Uma situação recorrente nesse sentido é a descredibilização de iluminadoras por técnicos montadores no ambiente de trabalho. A iluminadora curitibana Lucri Regiane (2021), por exemplo, relata que, no início de sua carreira, se viu levada a ocultar a autoria de seu projeto de luz durante a montagem para que suas escolhas técnicas e estéticas pudessem ser respeitadas e executadas corretamente.

A esse respeito, na roda de conversa intitulada IluminadorA: a trabalho dobrado de ser uma mulher, promovida pelo projeto Autobiografia de Todas Nós, iluminadores presentes argumentaram que todo profissional precisa comprovar sua competência em uma montagem para ser respeitado, porém sabemos que no caso das iluminadoras mulheres, o que se pede, subjetivamente, é que ela comprove ser capaz apesar de ser mulher. Devese considerar ainda que, uma vez que a criação de luz tem mais prestígio do que a técnica, sendo considerada hierarquicamente superior, quando homens se veem sob a liderança e comando de uma mulher, muitas vezes acabam por transformar o ambiente de trabalho em um lugar desconfortável (silenciando, questionando e invalidando sua fala) ou insalubre (objetificando, sexualizando e assediando seu corpo). Como resistir ou reagir a essas atitudes pode colocar a montagem em risco e vir a alterar o resultado final entregue ao público durante o espetáculo, é comum que profissionais mulheres se calem, ignorem ou sucumbam aos desagradáveis comportamentos masculinos em função de verem o trabalho concluído com êxito. A iluminadora curitibana Nadia Luciani (2021) revelou ter se dado conta de quantas vezes sucumbiu e até corroborou com piadas e comentários sexistas, feitos em tom sarcástico ou jocoso, assumindo serem parte de um comportamento masculino normal e aceitável, mais uma prova da submissão e resiliência feminina face ao machismo, principalmente nas gerações mais velhas.

Alguns homens que participaram do evento reconheceram-se machistas, comprometendo-se a mudar suas atitudes no ambiente de trabalho, mas outros, no entanto, afirmaram incisivamente não reproduzirem comportamentos machistas. Assegurando terem consciência da gravidade do assédio, disseram acreditar que, fora isso, homens e mulheres têm as 
mesmas condições de trabalho. Alguns deles ainda, frente à revelação de situações sofridas por mulheres nesses ambientes, demonstraram revolta e argumentaram que homens de verdade deveriam zelar pela integridade da mulher ou, ainda, que ser cavalheiro significa ajudar e proteger as mulheres. O cavalheirismo é um código de conduta cuja premissa atesta que a pessoa mais forte, capaz ou apta deve ajudar a mais frágil, incapaz e inapta. A construção social de gênero entende as mulheres como dignas desses atos cavalheirescos, reforçando o pressuposto de fragilidade e dependência. $O$ cavalheiro é um homem que não vê a mulher como igual, mas se sente superior a ela. Se a gentileza, e não o cavalheirismo, fosse o código de conduta, seria comum, nas montagens de luz, homens carregarem escadas para outros homens e receberem com naturalidade a ajuda de mulheres. $O$ cavalheirismo é uma forma de sexismo que, ao mesmo tempo que recompensa mulheres por desempenharem bem seus papeis de mulher, pune as que não se comportam de acordo com os padrões e ideais machistas, caracterizando o sexismo hostil e, no seu extremo, o feminicídio.

Sob um outro aspecto, mas também relacionado ao mesmo tema, os debates sobre roupas adequadas para mulheres em montagens de luz demonstram ainda mais preconceitos. É comum ouvir que alguns trajes e acessórios não são apropriados para o trabalho, e isso vai além de questões de segurança e/ou de conforto. Sugerir que alguma profissional possa ir trabalhar de saia, salto alto e cabelos soltos, uma imagem estereotipada de mulher hiperfeminina, é algo muito distante da realidade. Além disso, é preciso entender que há uma grande diferença entre vestir-se adequadamente e precisar masculinizar-se para ser bem aceita no ambiente de trabalho. Afinal, o que seria uma roupa adequada para uma montagem de luz? Ela é a mesma para homens e mulheres? Bermuda e regata, por exemplo, são itens aceitáveis como vestimenta para homens em dias quentes, mas se tornam impensáveis para mulheres, principalmente se elas não têm familiaridade com a equipe masculina a ponto de sentir-se à vontade para vestir-se desta forma.

Algumas vezes, as exigências a respeito da vestimenta de mulheres iluminadoras podem parecer estar relacionadas a fatores de segurança, mobilidade e conforto, mas na verdade camuflam atitudes de controle e 
opressão, impostas para ocultar ou disfarçar formas e características do corpo feminino com sutiãs, decotes fechados, roupas compridas e com mangas, calças largas, cabelos curtos ou presos, entre outras. Muitas dessas escolhas são feitas pelas próprias mulheres, ainda que inconscientemente, para evitar comentário maliciosos ou problemas de assédio e não comprometer a fluidez na realização do trabalho. É comum que, para exercer funções técnicas, associadas à lógica e à força física masculinas, ou a coordenação da montagem, que pode representar certo status de poder, as mulheres tenham que se rebelar e romper com o estereótipo de gênero feminino em vigor. Quando isso acontece, tanto no que diz respeito à mulher quanto a outras minorias, o que brota como respostas sociais são bullying, exclusão, discriminação, agressão ou violência psicológica e física, reações extremistas que têm como objetivo fazer com que esse sujeito se reenquadre e se adeque à norma social vigente. Esse processo de rejeição e violência afeta diretamente o psicológico e a autoestima da pessoa agredida, gerando insegurança e prejudicando a sua autonomia tanto na sociedade quanto no mercado de trabalho.

\section{DEPOIMENTOS - MOVIMENTOS DAS MULHERES ILUMINADORAS}

A pandemia da Covid-19 no Brasil impactou fortemente diversos setores econômicos do país nos anos de 2020 e 2021. Com a necessidade do isolamento social, as atividades artísticas foram inicialmente interrompidas e depois suspensas, o que inviabilizou a manutenção e a oferta de postos de trabalhos, bem como a garantia de renda para quem exerce funções técnicas e criativas no setor cultural. Como forma de se manter em atividade, profissionais de diferentes áreas começaram a conceder entrevistas e oferecer palestras, aulas e cursos online. Essas ações fizeram com que o trabalho de quem atua por trás dos bastidores começasse a ganhar visibilidade e ser amplamente discutido, tantos pelos próprios profissionais e seus pares quando pelo público em geral. Tanto atividades desse tipo quanto a possibilidade de migração do teatro presencial para o formato digital se 
intensificaram com a abertura de editais emergenciais específicos para as artes e a cultura ${ }^{7}$. No campo da iluminação cênica, foram promovidos eventos, treinamentos, espaços de debate, além de posicionamentos em defesa de políticas públicas de apoio financeiro emergencial ao setor cultural. Esses acontecimentos ofertados remotamente abriram espaço para que muitas mulheres iluminadoras fossem convidadas para apresentar seus trabalhos artísticos e de pesquisa, além de compartilhar histórias e vivências nos palcos.

Simultaneamente, surgiram movimentos organizados por e para mulheres ${ }^{8}$ em diferentes regiões do país. Criados com o intuito de dar voz a iluminadoras, acabaram por identificar semelhanças e fomentar a discussão de como o gênero é determinante nas experiências de vida e nas vivências profissionais dessas mulheres. Esses movimentos se opuseram, pelos diálogos e trocas que fomentaram, ao mito da rivalidade feminina, percebido como um instrumento usado para corroborar com a manutenção da dominação masculina ao reconhecer a competição como um comportamento natural entre as mulheres (MARTINS, 2019, p. 29). Ao negar a imposição da sociedade patriarcal de que somos rivais, pudemos nos reconhecer como aliadas e parceiras de trabalho, criando novas formas de relacionamentos e ampliando as colaborações em projetos coletivos.

Diante do individualismo e da competitividade, importa olhar para o
coletivo que gera espaços de comunhão, construções e decisões
que são frutos da parceria, do diálogo, do poder do amor, da força
que provém da convivência, da mutualidade e sororidade. Apoio,
empatia, solidariedade são elementos libertadores para a ética
feminista sendo que a partilha do conhecimento e de experiências
de vida e sabedoria liberta e empodera para o crescimento. Essa
partilha não ocorre de forma isolada, mas em grupo, onde mulheres
planejam e agem juntas, em sororidade. (SCHERER, 2017, p. 115) O ambiente de compartilhamento de experiências e histórias relacionadas ao trabalho com a iluminação cênica gerou uma potente rede de

\footnotetext{
${ }^{7}$ Através de pressões da classe artística, foi implementada a Lei Aldir Blanc - Lei no 14.017, de 29 de junho de 2020, definindo ações emergenciais destinadas ao setor cultural durante o estado de calamidade gerado em função da pandemia da Covid-19.

${ }^{8}$ É importante citar que esses movimentos de, por e para mulheres não seguem, necessariamente, teorias feministas, mas buscam a emancipação das mulheres no mercado de trabalho. No entanto, a análise dos projetos mencionados neste artigo, todos voltados para as profissionais da iluminação cênica, foi feita a partir de uma perspectiva feminista.
} 
mulheres em torno deste tema. Para a feminista Joice Berth, "entender a autoavaliação de si mesmo e, principalmente, conseguir detectar aquilo que o sistema conseguiu adulterar em nós mesmos, é um ato político importante" (BERTH, 2019, p. 141). Ao analisar o constructo cunhado por Paulo Freire no seu sentido transformador, a escritora afirma que o empoderamento se refere ao processo vivido por um sujeito que toma consciência de seus papéis sociais e do sistema que o sustenta, tendo a liberdade como práxis e resultando na transformação do sujeito, individual ou coletivamente, em agente ativo. Berth reforça ainda que o individual e o coletivo são partes indissociáveis do processo de empoderamento, um não se aplica nem se estabelece sem o outro. Quando mulheres iluminadoras compartilham suas experiências, empoderam-se mutuamente, pois trocam vivências, estratégias e saberes. Aprender de, com e entre mulheres altera a relação com o conhecimento, gerando pertencimento e orgulho de classe, o que acaba por incentivar o ingresso e a permanência dessas mulheres no mercado de trabalho da luz.

\section{1ำ MOVIMENTO: Mulheres na Luz}

Um dos primeiros movimentos a surgir no Brasil direcionado à divulgação do trabalho de iluminadoras foi o Mulheres na Luz em 2017. Ligia Chaim, iluminadora em São Paulo há 18 anos, sentiu-se incomodada ao perceber que um perfil no Instagram procurava trazer visibilidade a trabalhos na iluminação cênica, mas todos assinados por homens. Como resposta, Ligia criou o perfil @mulheres_na_luzcom o objetivo de divulgar também o trabalho de mulheres. Inicialmente, a ideia era compartilhar fotos de projetos dessas iluminadoras, até que Lua Melo Franco, atriz, iluminadora cênica e produtora técnica de eventos virtuais, natural de Minas Gerais, entrou para a equipe. Lua havia notado a presença de mulheres na área de iluminação ao participar, em 2019, do evento catarinense A Luz em Cena. Conheceu diversas mulheres que já trabalhavam na área e, com o objetivo de estudá-las e conhecê-las melhor, passou a convidá-las para postarem seus trabalhos no seu próprio 
perfil do Instagram articulando, com essas postagens, uma rede de iluminadoras "[...] para cada mulher convidada eu pedia que indicasse mais três [...] e ia fazendo o mapeamento" (FRANCO, 2021). As postagens iniciais previam apenas fotos e textos das obras dessas mulheres até que Dodi Leal, iluminadora paulista, foi convidada para participar do projeto.

[...] ela [Dodi] já estava nesse rolê de live [...] a galera que viu a chamada para a postagem da Dodi, [...] cismou que era live. Ela me ligou perguntando se não era melhor fazer uma live, já que era isso que a galera estava pedindo. E a gente fez, essa foi a primeira live do Mulheres na Luz, no meu perfil ainda. [...] Quando eu fui convidar outras mulheres, elas queriam live também. [...] Quando chegou a vez da Nadja Naira, ela me apresentou o trabalho da Ligia Chaim no Mulheres na $L u z$ [...] aí eu falei 'Ligia, vamos juntar?', e ela topou. Eu migrei pro perfil @ mulheres_na_luz e comecei a fazer as lives lá." (FRANCO, 2021)

O movimento repercutiu e a iluminadora cearense Aline Rodrigues foi convidada para colaborar com seus vídeos e textos no perfil Diário de $L u z$, também criado por Ligia Chaim para compartilhar dicas sobre o trabalho na área da iluminação. Os vídeos da série Mulher em Foco ${ }^{9}$ abordavam questões técnicas como eletricidade, equipamentos de segurança e construção caseira de equipamentos luminosos e tinham como objetivo formar e orientar mulheres iluminadoras, principalmente as iniciantes no ramo.

Em uma das lives, a iluminadora Sinésia Ventura sugeriu a criação de um grupo de WhatsApp com essas mulheres. Lua criou o grupo com 15 contatos, Sinésia adicionou mais 10 e atualmente, com a participação de 173 mulheres, ele se tornou uma rede de contato direta e ativa entre iluminadoras, montadoras, programadoras, operadoras e técnicas de luz. Além disso, o grupo serve ainda como canal de amparo e ajuda, forma de divulgação dos trabalhos e espaço seguro para o compartilhamento de experiências, gerando um sentimento de pertencimento e fortalecendo as vozes e reivindicações das mulheres. É possível comparar esse movimento aos Grupos de Conscientização surgidos na década de 60:

\footnotetext{
${ }^{9}$ Esta vertente do movimento se transformou no "Artesania da luz em Tempos de Pandemia", um vídeo-doc-oficina, dividido em três episódios que mesclam a construção de equipamentos artesanais de luz e uma conversa com artistas ligadas às artes cênicas sobre o contexto da arte na pandemia. Disponível no canal do Youtube de Aline Rodrigues.
} 
[...] comunicação e diálogo eram centrais na pauta das sessões de conscientização. Em vários grupos, a norma era honrar a voz de todas. As mulheres se revezavam para falar, assegurando que todas pudessem ser ouvidas. Essa tentativa de criar um modelo não hierárquico de debate foi positiva ao dar a todas as mulheres uma chance de falar. [...] Discussões argumentativas eram comuns no GC, porque era a maneira que buscávamos para esclarecer nossa compreensão coletiva da natureza da dominação masculina. Somente com discussões e desacordos poderíamos começar a encontrar um ponto de vista realista sobre exploração e opressão de gênero. (HOOKS, 2020, p. 26)

Lua relatou ter recebido alguns questionamentos sobre a escolha por falar de gênero, visto que a temática do canal era a iluminação. Foi quando percebeu que nunca havia colocado, nos roteiros de perguntas para as lives, uma única questão específica sobre gênero, “...só que o assunto surgiu pela urgência de falar, faz parte do trabalho. [...] O Mulheres na Luz é como um despertador, ele acorda. Acorda para a questão." (FRANCO, 2021). O perfil do Instagram, que atualmente conta com mais de duas mil seguidoras e seguidores, tem realizado chamadas para ampliar essa rede de mulheres buscando iluminadoras de estados que ainda não foram apresentadas nas lives.

\section{MOVIMENTO: IIUMINA!}

Larissa Lacerda, iluminadora de Salvador, iniciou sua carreira na área da iluminação cênica como técnica. Ela participou de uma oficina ministrada por João Batista, iluminador soteropolitano e foi quando aceitou o convite para acompanhar uma montagem ao final do curso que se encantou: "[...] a gente até tenta escapar, mas o teatro me pegou. [...] A luz me deu a luz" (LACERDA, 2021). Por ter começado como técnica, sempre lutou pelos direitos de quem exerce essa função. Segundo ela, por questões de hierarquia social, a técnica é vista como um sub-trabalho, com jornadas mais longas, pouco reconhecimento e sem as devidas condições de segurança.

Larissa disse ter recuperado seu ânimo quando recebeu o convite do Mulheres na Luz. Acompanhar o crescimento dessa rede de comunicação entre mulheres a inspirou para pensar em ações formativas/educativas na área de iluminação cênica. Com recursos oriundos da Lei Aldir Blanc, Larissa 
juntou-se a Milena Pitombo e Maria Carla, ambas atrizes e iluminadoras, para criar o iluMINA!, cujas informações, ações e produções são publicadas no perfil do Instagram @projeto.ilumina. Produzido pela Dimenti Produções, o projeto foi dividido em duas etapas: na primeira, foram selecionadas 60 mulheres para participar de uma oficina de introdução aos conceitos básicos da iluminação cênica; na segunda, 12 dessas mulheres receberam uma bolsa e uma mentoria para o desenvolvimento de um trabalho artístico. Voltado apenas para mulheres da Bahia, o projeto teve grande repercussão, recebendo mais de 300 inscrições graças à articulação de mobilizadoras locais - 7 artistas mulheres, uma de cada macrorregião baiana. Larissa compartilhou que a metodologia do projeto foi sempre pensada para preservar a autonomia das participantes no processo criativo. Com os conhecimentos adquiridos na primeira etapa, na segunda elas puderam se dedicar à experiência do processo da criação da luz e investigar as variáveis que interferem na visualidade de um projeto artístico.

Duas características do projeto, uma financeira e outra pedagógica, se relacionam diretamente com a discussão proposta neste artigo. $O$ apoio financeiro, além de permitir uma maior dedicação das participantes, também serviu como forma de validação e reconhecimento das suas ideias, fortalecendo sua autoestima como profissionais do ramo da iluminação. Segundo Larissa, "A gente sabe, na nossa pele, no nosso corpo, da dificuldade de criar parceria. A gente não é forjada nesse sentido, de acreditar que as pessoas podem trabalhar a favor da sua ideia" (LACERDA, 2021). Em segundo lugar, a mentoria ressaltou importância na iluminação da relação mestre-aprendiz, neste caso, iluminadora-assistente. Quando é criado um ambiente favorável para a aprendizagem, no qual o erro e as dúvidas são compreendidas como parte do processo de experimentação, incentiva-se a curiosidade e o interesse, transformando a relação de mestre-aprendiz numa dinâmica colaborativa baseada em sintonia e empenho mútuos. Segundo Souza (2018, p. 42), o estabelecimento de confiança, adquirida no convívio cotidiano e dedicação extensiva, implica em compreender o processo formativo enquanto compartilhamento de experiências de vida, para além de uma experiência pedagógica. $\mathrm{O}$ fato de todas as mentoras e aprendizes 
serem mulheres, ensinando e aprendendo a serem iluminadoras pelas perspectivas simultâneas da técnica e do gênero, possibilitou um ambiente fértil para a criação, experimentação e aprendizado, no qual foi possível uma atuação como "mestre responsável também pela educação sociocultural de seus aprendizes no exercício desta profissão." (SOUZA, 2018, p. 44)

\section{3ำ MOVIMENTO: Mulheres na Técnica PA}

A ideia que originou o movimento surgiu de conversas entre Natasha K. Leite, artista-iluminadora-pesquisadora e técnica de iluminação cênica há 13 anos na cidade de Belém, e uma colega de profissão, Aline Rodrigues, que desde 2018 estava no mesmo processo de articulação de mulheres iluminadoras em Fortaleza. Juntamente com o Coletivo Alumiá, criado em parceria com Julia Freitas, Malu Rabelo e Danielle Queiroz, Natasha realizou um levantamento sobre o quantitativo de mulheres atuantes em atividades técnicas na região. "A ideia de usar o mesmo nome no Pará e no Ceará reforçava a intenção de promover um intercâmbio entre as regiões" (LEITE, 2021). O formulário utilizado para coletar as informações foi elaborado em 2019 em colaboração com muitas outras iluminadoras. Em 2020, a equipe realizou um encontro presencial, mas com a chegada da pandemia toda comunicação e divulgação foi realizada pelas redes sociais. Com o objetivo de promover a reflexão e a mobilização de mulheres por meio do perfil do Instagram @mulheresnatecnica_pa, o movimento, criado sem incentivo financeiro público ou privado, tornou-se uma rede de apoio e visibilidade para mulheres técnicas de diversas áreas do segmento cultural da região. Proporcionando a troca de saberes, um banco de contato para contratação, garantia de visibilidade das profissionais da técnica e luta pelos direitos básicos para a atuação profissional, o perfil serviu de inspiração para outros estados aderirem ao movimento. O discurso de Natasha diante dessas mulheres foi embasado em muitas leituras vinculadas ao feminismo:

Sempre levantando a problematização da divisão social do trabalho e as desigualdades ainda cravadas por debaixo das estruturas de pensamento numa sociedade patriarcal $[. .$.$] . Mulheres que atuam$ 
no segmento cultural e de alguma forma se dedicam às atividades técnicas de criação e produção artística, tendem a lidar diariamente com problematizações que trazem em seus históricos um rastro do favorecimento de gênero pela divisão de trabalho. [...] Buscamos debater sobre direitos e responsabilidades profissionais, compartilhar experiências positivas e negativas, encorajar o autoconhecimento e a não competitividade entre nós, nos unindo em favor da visibilidade de nossas atividades pelos bastidores. [...] As vozes multiplicadas nesses projetos serão ouvidas e ecoarão por gerações. Os caminhos estão sendo preparados, no agora. (LEITE, 2021)

O movimento Mulheres na Técnica PA conta atualmente com um grupo de 66 mulheres da faixa etária entre 22 e 65 anos que possuem formação em ensino técnico profissionalizante e aprimoramento em mais de uma área de conhecimento. Esse movimento, assim como outros similares, coloca em evidência os efeitos da interseccionalidade na produção da desigualdade, tanto em relação à área técnica quanto à mulher no mercado de trabalho.

\section{4ำ MOVIMENTO: Autobiografia de Todas Nós}

O projeto Autobiografia de Todas Nós resultou do encontro e dos 30 anos que separam as iluminadoras-pesquisadoras Gabriela Valcanaia e Nadja Naira. A diferença geracional entre elas fez perceber como as questões relacionadas às mulheres na iluminação cênica são vistas de maneira diferente a depender, além da idade, das condições individuais das mulheres iluminadoras como raça, classe social, orientação sexual, identidade de gênero e regionalidade.

Em 2020, Naira preparou, para sua participação na live do Mulheres na $L u z$, uma retrospectiva de sua trajetória no teatro com foco nas mulheres que compartilharam sua história. Estimulada pela entrevistadora, convidou Gabriela para pensarem juntas em um modo de transformar aquela pesquisa biográfica em um material documental. O projeto, realizado no primeiro semestre de 2021 com recursos da Lei Aldir Blanc, pretendia repensar a história com foco nas mulheres para compreender como, a partir de uma, poderia ser possível compreender a realidade coletiva e plural de todas. $\mathrm{O}$ Autobiografia de Todas Nós floresceu, ainda, pelo desejo e mobilização coletiva para reverter o apagamento sistêmico da atuação das mulheres na 
iluminação cênica. Compartilhar e ouvir as histórias dessas iluminadoras se revelou como uma forma de criar conexões e sensibilizar homens e mulheres para suas diferentes experiências. Composto por quatro eixos, o projeto ofereceu espaço para dar voz às iluminadoras de Curitiba: um mini documentário apresentando as trajetória dessas mulheres; um mapeamento documental das iluminadoras, técnicas e professoras de iluminação cênica da região; duas rodas de conversa online com convidadas sobre os temas IluminadorA: como começa e IluminadorA: o trabalho dobrado de ser uma mulher, um ensaio sobre questões de gênero a partir de uma narrativa autobiográfica e de uma memória coletiva de mulheres artistas.

O mini-documentário Depois de Nós ${ }^{10}$ reúne seis mulheres iluminadoras de diferentes gerações que contam suas histórias pessoais e profissionais com a luz e com as questões complexas de ser uma iluminadora mulher. O ensaio autobiográfico $A$ história de quem agiu no breu propõe repensar a maneira como a memória coletiva das/sobre mulheres ao longo da história afetam o que imaginam e desejam para si e para o mundo. A autora Gabriela Valcanaia parte de memórias pessoais para especular, por meio de contundentes perguntas retóricas, a aparente ausência/inatividade das mulheres ao longo da história:

\begin{abstract}
Como viabilizar o acesso/entrada das mulheres no mercado de trabalho? Como incentivar e remunerar seu desenvolvimento? Como punir seriamente casos de agressão ou assédio, garantindo plena execução de sua função? Como ampliar as possibilidades de crescimento de carreira? Ao incluirmos mulheres artistas (com e sem filhos) nos projetos culturais não estamos apenas melhorando a vida dessas mulheres, mas melhorando a arte. O que é produzido é melhor porque é mais diverso. Se eu soubesse disso antes, se muitas soubessem, talvez tivéssemos equipes mais diversas no governo e até uma presidenta do mundo, quem sabe. Se as mulheres (também) governassem o mundo, ele certamente seria outro. Mas o que o desejo de governo das mulheres construiria? (VALCANAIA, 2021)
\end{abstract}

\footnotetext{
${ }^{10}$ Iluminadoras entrevistadas: Fábia Regina, Gabriela Valcanaia, Lucri Reggiani, Nadia Luciani, Nadja Naira e Semy Monastier. Roteiro: Nina Rosa Sá. Diretora de vídeo e montagem: Carol Winter. Composição de trilha e edição de áudio: Erica Silva. Produção: Janaína Micheluzzi. Tradução em LIBRAS: Talita Sharon Simões. Disponível em todasnos.art na aba Vídeos: https://todasnos.art/\#video-0.
} 
O mapeamento, terceiro eixo do projeto, foi realizado pela pesquisadora Milena Sugiyama por meio de um formulário com três etapas: a primeira com dados como nome, idade, função e experiência na área; a segunda com perguntas sobre processos de criação e pesquisas desenvolvidas pelas participantes; e a terceira a respeito de casos de assédio, violência física ou mental e descredibilização sofridos por elas. As duas primeiras etapas foram usadas na composição do perfil dessas mulheres na plataforma digital do projeto (todasnos.art) e a terceira para fins de pesquisa e levantamento de dados. Alguns fatos flagrantes resultantes desta pesquisa foram que, das 28 iluminadoras que participaram do mapeamento, apenas 5 se identificam como não-brancas; todas se auto qualificaram como mulheres cisgêneras e a maioria revelou já ter passado por situações desconfortáveis, no meio profissional ou não, provocadas por homens. Com objetivos e implicações semelhantes, a iluminadora carioca Brisa Lima criou um formulário de mapeamento de mulheres iluminadoras pretas brasileiras ${ }^{11}$.

Outra revelação do mapeamento feito foi a menção à oficina oferecida pelo LABIC - Laboratório de Iluminação Cênica da FAP/UNESPAR como início do processo de formação de muitas das iluminadoras curitibanas. $O$ LABIC é um projeto de extensão universitária criado e coordenado pela Prof. ${ }^{\text {a }}$ Dr. ${ }^{\text {a }}$ Nadia Moroz Luciani que, além de auxiliar os/as/es estudantes da faculdade em seus projetos acadêmicos, realiza anualmente uma oficina profissionalizante e gratuita de iluminação cênica aberta para a comunidade. Ministrada pela coordenadora do projeto com carga horária de 60 horas, a oficina tem sido responsável, desde sua primeira edição em 2010, pela formação de profissionais, muitas delas mulheres, tornando-se referência no ensino de iluminação cênica na cidade. O que cabe destacar em relação à essa formação é que ter uma mulher como mestre e exemplo, além de constituir um fator importante para a autoconfiança e a construção da autoimagem de futuras iluminadoras, ainda tem o efeito de quebra de preconceitos de futuros iluminadores. Ao incentivar aprendizes a participarem de sues processos de criação e montagens, Nadia proporciona ainda uma

\footnotetext{
${ }^{11}$ Disponível no seu perfil do Instagram: https://www.instagram.com/iluminadoraspretas/.
} 
forma de aprendizagem emancipadora, ligada não apenas ao ensino das técnicas e tecnologias, mas à formação consciente, completa, abrangente $\mathrm{e}$ inclusiva de futuros profissionais, homens e mulheres.

\section{PERCEPÇÕES}

Analisar os movimentos de mulheres iluminadoras pelo viés de teorias feministas permitiu revelar a desigualdade ainda presente na realidade social brasileira com destaque para o mercado de trabalho da iluminação cênica. Apesar das mulheres terem, historicamente, se desprendido do isolamento doméstico e passado a garantir o incremento ou até a totalidade da renda familiar, a inclusão de mulheres no mercado de trabalho não significou sua plena autonomia, além de ter tido, como efeito secundário, a sobrecarga de trabalho. Assim sendo, é preciso que se reconheçam as diferenças sociais de homens e mulheres para que se criem políticas e ações efetivas no sentido da igualdade, do respeito, da dignidade e da remuneração justa de mulheres.

No âmbito da iluminação cênica, as desigualdades ficaram ainda mais evidenciadas pela emergência de movimentos e projetos idealizados, liderados e compostos por mulheres durante a pandemia da Covid-19. Ao Ihes dar voz em lives, entrevistas, textos e depoimentos, eles permitiram demonstrar como as histórias, aparentemente individuais e isoladas, eram, na realidade, comuns a diferentes mulheres. Da profusão dessas ações surgiu um discurso diverso, marcado pelas relações de classe, raça, geração, orientação sexual e regionalidade, reforçando o fato de que o objetivo dos movimentos nunca foi a homogeneidade. Segundo Spivak (2010, p. 42), o interesse das mulheres ao se unirem não surge de um instinto de classe, mas de um interesse sistêmico e heterogêneo, que faz com que emerjam diferentes posicionamentos, cujo objetivo comum é lutar contra a opressão do sistema patriarcal e capitalista. Ao contarem suas histórias por uma perspectiva pessoal, essas mulheres marcam sua posição como narradoras e não pressupõem, necessariamente, que ao dizerem sobre si, dizem sobre todas. 
Elaborar esse pensamento é parte do meu processo de autoconstrução, mas não é algo a ser seguido. Escrevo para que você que me lê possa também se elaborar a partir das suas palavras e para que possamos colocá-las em diálogo. Para que possamos trocar ideias feministas e repovoar nossos imaginários. Para que não mais repliquemos teorias criadas por outros, mas dialoguemos com essas teorias e também com vivências de outras pessoas. (VALCANAIA, 2021)

Refletir sobre as relações interpessoais tendo o gênero como parâmetro de análise é fundamental para que o sexismo mascarado de gentileza não seja confundido com atitudes de apoio à luta pela autonomia e emancipação da mulher. É notória a importância de que a conscientização e as discussões de gênero aconteçam com mais frequência, sendo, contudo, indispensável que ela deixe a esfera individual e se direcione para o coletivo, envolvendo e combatendo a estrutura patriarcal e capitalista que reforça e beneficia posturas de opressão e de submissão das mulheres. Apesar das diferenças físicas entre homens e mulheres na sua experiência com a cisgeneridade ou com a transgeneridade, nenhum tipo de tratamento especial deveria ser oferecido a priori. Diante de uma situação duvidosa, basta se perguntar se a atitude de proteção ou ajuda seria a mesma independente da pessoa agraciada ser mulher ou homem ou da sua estrutura e condição física. Se não for esse o caso, fica evidenciado um ato de cavalheirismo que nada tem a ver com gentileza, mas com a manutenção do machismo e do sexismo no ambiente de trabalho. Essas atitudes são a parte não dita ou em branco (SPIVAK, 2010, p. 107) do discurso machista, sobre as quais ele se constrói e se mantém. A única forma de promover alguma transformação a respeito é por meio da tomada de consciência e, portanto, da aproximação com teorias feministas, permitindo que elas sejam colocadas em prática com organicidade:

\footnotetext{
A formação passa não só por compreender o trabalho que as mulheres têm feito, mas também quais são as formas de violência que nós praticamos cotidianamente, seja nos territórios, seja na atuação política. A violência física é a mais nítida, mas temos também a violência sexual, patrimonial e simbólica de maneira geral. Essas formas de violência não estão claras para nós homens: elas precisam ser ditas, e uma forma de dizer é com a formação política que requer estudo, leitura, curso. E nossa organicidade precisa ser reflexo dessa transformação de nosso movimento com bases feministas. [...] Precisamos reorientar toda a divisão sexual
} 
do trabalho que há na nossa lida do dia a dia. Precisamos também mudar a forma como a renda gerada pela família - e os investimentos - são definidos e destinados. [...] Da mesma forma, nas nossas lutas a divisão de todas as tarefas deve buscar superar a definição machista de tarefas específicas para homens. [...] As metodologias das reuniões, as dinâmicas dos encaminhamentos, as formas de construir o trabalho de base... não basta ter mulheres na organicidade, se a forma dessa organicidade for masculinizada. É necessário nos revolucionarmos internamente. (ZARREF, 2020)

Apenas por meio de informação, conhecimento, estudo e debate será possível alterar valores e comportamentos sociais tão arraigados. São discussões em rodas de amigos, círculos sociais e familiares, mas que devem ir além, com atitudes reais de contratação, leitura, referências, citações e apoio a mulheres. Somente ações como essas permitirão alterar a vida em sociedade e o quadro atual do mercado de trabalho da iluminação cênica. Sem investigações sérias sobre a desigualdade de gênero, não há como efetivar políticas de combate às desigualdades ou de incentivo a práticas combativas. É preciso tirar o véu de igualdade existente e admitir que a desigualdade existe é o primeiro passo para combatê-la. Não temos notícias, no Brasil, de estudos e dados científicos que conduzam a conclusões efetivas sobre o assunto, então permanecemos à mercê de depoimentos, suposições e vozes soltas ao vento, sem ecos que lhes sustentem ou fortaleçam. É justamente contra a falta de informação que surgem movimentos que buscam expor a realidade coletiva por uma perspectiva individual de mulheres que, com isso, legitimam a si mesmas na coletividade.

Eduardo Galeano (1994) cita Fernando Birri para lembrar que a utopia está lá no horizonte. Se nos aproximamos dois passos, ela se afasta dois passos. Caminhamos dez passos e o horizonte corre dez passos. Por mais que caminhemos, jamais alcançaremos. Para que serve a utopia? Serve apenas para que não deixemos de caminhar. Sigamos, então! Sigamos em direção à utopia de um mundo igualitário no qual seja possível lutar e vencer. 


\section{REFERÊNCIAS}

BEAUVOIR, Simone de. O segundo sexo: fatos e mitos. Tradução: Sérgio Milliet. Rio de Janeiro: Nova Fronteira, 2016.

BERTH, Joice. O que é empoderamento? Belo Horizonte: Letramento, 2018. FORJAZ, Cibele. À luz da Linguagem. A lluminação Cênica: de Instrumento da visibilidade à 'Scriptura do visível' \& outras poéticas da luz. Tese de Doutorado. Programa de Pós-Graduação em Artes Cênicas, Escola de Comunicação e Artes. São Paulo: USP, 2013.

FRANCO, Lua de Melo. Entrevista não publicada, concedida a Milena Sugiyama. Curitiba, 06 de abril de 2021.

GALEANO, Eduardo. Para que serve a utopia? Disponível em: https://www.revistaprosaversoearte.com/para-que-serve-a-utopia-eduardo-galeano/. Acesso em: 21/9/2020.

HOOKS, Bell. O feminismo é para todo mundo: políticas arrebatadoras. Tradução Bhuvi Labanio. Rio de Janeiro: Rosa dos Tempos, 2020.

LACERDA, Larissa. Entrevista não publicada, concedida a Milena Sugiyama. Curitiba, 06 de abril de 2021.

LEITE, Natasha K. Entrevista não publicada concedida a Milena Sugiyama. Curitiba, 04 de abril de 2021.

LUCIANI, Nadia. O discurso da luz: vídeo depoimento com a iluminadora Nadia Luciani. Depoimento concedido a Larissa Mayra de Lima e Halanna Aguiar para o webdocumentário do projeto Mulheres de Teatro. Curitiba, 2015. Disponível em: https://vimeo.com/mulheresdeteatro.

LUCIANI, Nadia Moroz. Iluminação Cênica: a performatividade da luz como elo entre a cena e o espectador. Tese de Doutorado. Programa de Pós-Graduação em Artes Cênicas, Escola de Comunicação e Artes. São Paulo: USP, 2020.

LUCIANI, Nadia. Depois de nós. Depoimento concedido a Nina Rosa Sá para o documentário do projeto Autobiografia de Todas Nós. Curitiba, 2021. Disponível em: https://todasnos.art/\#video-1.

MARTINS, Lorena Gabriela Santos. Sororidade na educação: uma experiência com oficina de empoderamento feminino. Dissertação de Mestrado - Programa de Pós-Graduação em Tecnologias, Comunicação e Educação, Faculdade de Educação. Uberlândia: UFU, 2019. 
MONTALI, L. Mudanças na família, no mercado de trabalho e nos arranjos familiares. In: LEONE, E. T.; KREIN, J. D.; TEIXEIRA, M. O. (Org.). Mundo do trabalho das mulheres: ampliar direitos e promover a igualdade. Brasília: Secretaria de Políticas do Trabalho e Autonomia Econômica das Mulheres; Campinas, SP: Unicamp. IE. Cesit, 2017, p. 39-6.

REGIANE, Lucri. Depois de nós. Depoimento concedido para o documentário do projeto Autobiografia de Todas Nós. Curitiba, 2021. Disponível em: https://todasnos.art/\#video-1.

SCHERER, Cristina. Princípios da Sororidade na Vida e na Bíblia. Congresso latinoamericano de Gênero e Religião, 5., 2017, São Leopoldo. Anais do Congresso Latino-Americano de Gênero e Religião. São Leopoldo: EST, v. 5, 2017. I p.112127.

SPIVAK, Gayatri Chakravorty. Pode o subalterno falar? Belo Horizonte: UFMG, 2010.

SOUZA, Fernanda Guimarães Mattos. Gambiarras de Luz: reflexões sobre a formação do iluminador cênico sob a ótica de três gerações cariocas. Dissertação de Mestrado em Artes. Programa de Pós-Graduação em Artes da Cena, Escola de Comunicação. Rio de Janeiro: UFRJ, 2018.

TRUTH, S. E não sou uma mulher? Tradução de Osmundo Pinto. Geledes, 2014. Disponível em: https://www.geledes.org.br/e-nao-sou-uma-mulher-sojourner-truth/. Acesso em: 19/05/2021.

VALCANAIA, Gabriela. A história de quem agiu no breu. Ensaio publicado no site todasnos.art. Curitiba, 2021. Disponível em: https://todasnos.art/\#textos.

WOLF, Naomi. O mito da beleza: como as imagens de beleza são usadas contra as mulheres. Brasil: Rocco, 1992.

ZARREF, Luiz. O homem precisa abrir mão do seu privilégio. Entrevista concedida a Alan Tygel. 2020. Disponível em: https://mst.org.br/2020/03/12/o-papeldo-homem-na-luta-feminista/. Acesso em 24/05/2021. 